\title{
Cenplestao
}

\section{Desvendando as relações de outras disciplinas com ciência da informação: avaliação a partir da perspectiva internacional}

\author{
Wesley Rodrigo Fernandes \\ Doutor; Universidade Federal de Minas Gerais, Belo Horizonte, MG, Brasil; \\ wesleyronline@yahoo.com.br \\ Beatriz Valadares Cendón \\ Doutora; Universidade Federal de Minas Gerais, Belo Horizonte, MG, Brasil; \\ bcendon@gmail.com
}

\begin{abstract}
Resumo: O objetivo geral do artigo é investigar na literatura científica o uso do conhecimento produzido pela ciência da informação internacional por pesquisadores das demais áreas científicas. A pesquisa é realizada em duas etapas. Os dados analisados na primeira etapa são provenientes de uma análise de citações a artigos da área de ciência da informação do cenário internacional publicados entre 1997 e 2016 e presentes na Web of Science. Na segunda etapa, com o objetivo de determinar o tipo de relação (multi, inter ou transdisciplinar) estabelecida entre as citações de outras disciplinas e a ciência da informação, é realizada análise quantitativa em uma amostra não-probabilística por conveniência de $15 \%$ das citações de outras disciplinas a trabalhos provenientes da ciência da informação internacional identificados na primeira etapa. Ainda na amostra utilizada na segunda etapa, para os trabalhos das citações que apresentam propriedades indicativas de serem pesquisas construídas a base de uma relação interdisciplinar, é realizada uma análise qualitativa para determinar se elas são de natureza uni, inter, multi ou transdisciplinar. Como principais resultados destacam-se: a observação de uma tendência de crescimento das citações dos trabalhos internacionais da área pelas demais áreas do conhecimento científico, esse fato pode demonstrar que a ciência da informação internacional tem avançado teórica e metodologicamente de modo sistemático nesses últimos 20 anos; a verificação de uma expressiva utilização do conhecimento da ciência da informação internacional pelas demais áreas do conhecimento, indicando uma potencial relação interdisciplinar de outras disciplinas com a ciência da informação internacional. Entretanto, esta potencial relação interdisciplinar não é confirmada pela análise quanti-qualitativa realizada na segunda etapa da pesquisa.
\end{abstract}

Palavras-chave: Ciência da Informação. Interdisciplinaridade. Transdisciplinaridade. Pluridisciplinaridade. Epistemologia da Ciência da Informação. 


\section{Introdução}

$\mathrm{O}$ rótulo de área do conhecimento interdisciplinar foi conferido à Ciência da Informação $(\mathrm{CI})$ desde os primeiros conceitos, definições e debates acerca do novo campo (BORKO, 1968; CROSLAND, 1962; SHERA; CLEVELAND, 1977; TAYLOR, 1966).

Subsequentemente, outros pesquisadores nacionais e internacionais também enxergaram a área como interdisciplinar e ratificaram esse título (DING; PAN; YANG, 2016; HUANG; CHANG，2011; HUANG; CHANG，2012; MORAES; CARELLI, 2016; PINHEIRO; LOUREIRO, 1995; SARACEVIC, 1996).

Entretanto, esse rótulo conferido à área não é uma unanimidade entre seus pesquisadores, uma vez que a literatura também apresenta pesquisas que questionam o discurso afirmativo da característica interdisciplinar do campo ou até mesmo refutam por completo a existência dessa característica (BICALHO, 2009; GOMES, 2001; HIGINO; DUMONT, 2012; PAIM et al., 2001; SANTANA, 2012; SANTOS NETO et al., 2017).

Alguns trabalhos desta segunda corrente apontam que a CI busca muito mais teorias, conceitos e metodologias nas disciplinas com as quais tem alguma relação do que fornece a elas teorias, conceitos e metodologias. Essa constatação leva ao questionamento da interdisciplinaridade da área e à sugestão de que se analise também se há algum movimento dessas outras disciplinas em direção à CI numa perspectiva de integração de conhecimentos de maneira a propiciar um enriquecimento mútuo entre as disciplinas envolvidas.

A respeito de um diálogo interdisciplinar entre disciplinas Gomes (2001, p. 4) explica que:

\footnotetext{
Muitas vezes se confunde interdisciplinaridade com a mera incorporação de conceitos, teorias e métodos de uma disciplina por outra, ou com o esforço de pesquisadores que, no seu período de qualificação migram temporariamente para o interior de uma determinada área [...] Porém, deve-se colocar em foco que esse percurso ainda não caracteriza a interdisciplinaridade, no máximo a potencializa, sugere sua necessidade, oferece as condições necessárias ao seu aparecimento, que só se concretiza a partir do diálogo concreto entre as disciplinas que pode ser constatado quando conceitos, teorias, métodos e campos de investigação migram,
} 
transitam nos vários sentidos das "regiões fronteiriças" concretizando essa interdisciplinaridade.

Em seguida, a respeito das pesquisas sobre a interdisciplinaridade na CI o autor propõe que:

É preciso identificar as disciplinas que vêm de fato promovendo alterações em seus campos teórico-práticos a partir da incorporação dos resultados e teses produzidas no interior da ciência da informação, como também promovendo seus profissionais e pesquisadores à luz desse referencial, efetuando o que efetivamente pode ser compreendido como um diálogo interdisciplinar. (GOMES, 2001, p. 5-6).

Outro trabalho a propor que se analise os movimentos de outras disciplinas em direção à CI numa perspectiva de integração de conhecimentos e enriquecimento mútuo das disciplinas foi o de Santos Neto et. al. (2017). No referido trabalho os autores concluíram que seria "[...] fundamental verificar essa integração nas demais disciplinas que contribuem para o corpus da CI e não somente no contexto dela própria" (SANTOS NETO et al., 2017, p. 29). Os autores sugerem, ainda, que a investigação deva ser feita além das fronteiras da CI, com o objetivo de verificar quais disciplinas têm incorporado conhecimento da CI em sua área de origem.

Fica evidente que essas pesquisas que questionam o discurso afirmativo da interdisciplinaridade na CI contestam a metodologia utilizada em várias delas que apenas avaliam a utilização pela CI do conhecimento de outras disciplinas.

Isso ocorre sem efetivamente avaliar se essa utilização é promovida através de um relacionamento consciente entre as disciplinas, de forma a propiciar uma reciprocidade nas trocas, de modo que todas as partes envolvidas sejam transformadas, requisitos básicos para a ocorrência de uma pesquisa interdisciplinar.

As principais questões levantadas neste artigo surgem dessa divergência de entendimentos encontrada nas pesquisas que se propuseram estudar a interdisciplinaridade na CI.

Esses questionamentos advêm ainda da verificação de escassez de estudos que avaliem se as disciplinas recorrentemente listadas como as que promovem um diálogo interdisciplinar com a CI também utilizam do conhecimento 
produzido pela área, de forma a propiciar uma integração de teorias e metodologias e uma interlocução de pesquisas e pesquisadores que promovam um enriquecimento mútuo entre as disciplinas envolvidas.

As questões propostas nessa pesquisa visam descobrir se outras áreas científicas utilizam do conhecimento produzido na CI internacional para subsidiarem a construção de seus campos teórico, prático e metodológico? Em caso positivo, quais seriam essas áreas? Está essa utilização promovendo uma pesquisa interdisciplinar com o campo?

Este estudo teve como objetivo geral investigar, na literatura científica internacional, o uso do conhecimento produzido pela CI por pesquisadores das demais áreas científicas, para darem sustentação teórica, metodológica ou conceitual às suas pesquisas e se esse uso se concretiza numa perspectiva de integração de teorias e metodologias bem como de interlocução de pesquisas e pesquisadores de modo a propiciar um enriquecimento mútuo entre as partes envolvidas. Os objetivos secundários foram: (1) identificar quais áreas recorrem às descobertas da ciência da informação para discutirem sobre suas inquietações/problemas; e (2) verificar o nível de relação/interação disciplinar (multi/inter/trans) estabelecido entre as outras áreas do conhecimento com a CI internacional.

Assim, perante as justificativas da relevância da questão da interdisciplinaridade para o campo, que é um objeto de estudo da área presente desde a gênese da CI até as pesquisas atuais, a discordância entre as pesquisas sobre a CI ser ou não uma área científica interdisciplinar e a escassez de estudos que avaliam a existência de utilização do conhecimento produzido no escopo da CI por outras disciplinas numa perspectiva integrativa de conhecimentos e pessoas, esta pesquisa objetiva trazer subsídios que permitam avançar na discussão sobre essa temática de modo a ampliar os horizontes epistemológicos da área.

$\mathrm{O}$ artigo se estrutura da seguinte maneira: a primeira seção apresenta a justificativa, o problema de pesquisa, os objetivos gerais e específicos; na segunda seção são abordadas as correntes teóricas para questão da interdisciplinaridade e seus conceitos correlatos assumidos nessa pesquisa; a terceira seção trabalha uma 
série de artigos que apontam um relacionamento da CI com outras disciplinas numa perspectiva interdisciplinar; a quinta seção traz o percurso metodológico desenvolvido na pesquisa; na quinta seção são apresentados os resultados da pesquisa e na sexta seção serão apresentadas as conclusões da pesquisa.

\section{A interdisciplinaridade e seus conceitos correlatos}

Abordar a temática da interdisciplinaridade não é uma tarefa fácil, porque esse tema é sabidamente um termo "[...] que não possui ainda um sentido epistemológico único e estável [...]" (JAPIASSU, 1976, p. 72), "polissêmico" (BERTI, 2007, p. 100), “[...] escorregadio e de difícil compreensão epistemológica" (SILVA, 2013, p. 70), "multifacetado e polissêmico" (ZIMMERMANN; CARLOS, 2005, p. 1).

Além disso, a interdisciplinaridade dá margem a várias interpretações e significados uma vez que ela não apresenta uma definição única e ainda tem termos correlatos com significados e propósitos que dão margem a interpretações semelhantes.

Para facilitar a compreensão do que vem a ser esses termos Japiassu (1976), Fazenda (2011), Pombo (2004, 2008), Jantsch (1972), entre outros autores, explicam que esses movimentos surgiram como resposta à fragmentação do conhecimento e fazem parte de um "continuum" de níveis de gradações disciplinares que crescem de intensidade. Inicialmente haveria o nível do multi e pluridisciplinar, os quais representam interações disciplinares mínimas sem a ocorrência de integração mútua entre as disciplinas envolvidas. O nível seguinte seria o interdisciplinar, que exige um trabalho colaborativo entre as disciplinas envolvidas de modo a proporcionar um enriquecimento mútuo entre as partes. Por fim, se chegaria ao nível transdisciplinar, um nível de relações disciplinares sem fronteiras estáveis entre as disciplinas envolvidas.

Para um melhor entendimento desse trabalho, serão apresentados a seguir os elementos comuns ou características básicas para cada termo encontrados na literatura que norteiam o entendimento dessas temáticas e foram adotados nessa pesquisa. 
Os tipos de interação pluridisciplinar e multidisciplinar foram tratados como um só por representarem uma forma mínima de relação disciplinar (POMBO, 2008), ou pelo fato da diferença entre os dois termos ser mínima, fato explicado apenas pela “[...] maior ou menor aproximação ou 'afinidade' entre as disciplinas que estão interagindo" (BICALHO, 2009, p. 78). Em ambas perspectivas não há a ocorrência de integração mútua entre os conhecimentos das respectivas disciplinas envolvidas, na qual geralmente nenhuma disciplina sai enriquecida, ou apenas uma (DOMINGUES, 2005; JANTSCH, 1972; JAPIASSU, 1976; PIAGET, 1972; REPKO, 2012).

Os elementos comuns e características básicas que norteiam o entendimento da interdisciplinaridade nessa pesquisa adotados pelos autores Jantsch (1972), Piaget (1972), Japiassu (1976), Pombo (2004) e Repko (2008) são:

a) relação de duas ou mais disciplinas distintas (entenda-se disciplina como área do conhecimento) que se relacionam de forma consciente para atingir um objetivo comum;

b) há reciprocidade nas trocas, de modo que todas as disciplinas envolvidas são transformadas epistemologicamente, metodologicamente ou teoricamente;

c) produz um avanço cognitivo no entendimento da temática estudada a partir da interação, conversão e integração dos conhecimentos das disciplinas que estão se relacionando para esse objetivo;

d) a interdisciplinaridade não rompe com as disciplinas, ela apenas aproxima disciplinas distintas para em interação fornecer respostas mais "inteiras", "concertadas", "abrangentes" e "alargadas" a desafios complexos.

No tocante à transdisciplinaridade, ela seria o nível mais elevado nas relações disciplinares.

Porém as atuais estruturas das comunidades científicas, dos regimes pedagógicos e das escolas ainda não permitem que esse nível aconteça em sua plenitude, ou seja, um sistema de relações disciplinares sem fronteiras estáveis entre as disciplinas (uma vez que o transdisciplinar se preocupa com o 
conhecimento produzido entre as disciplinas, através das disciplinas e além das disciplinas), com níveis e objetivos múltiplos coordenando todas as disciplinas em busca de uma finalidade comum ou uma teoria global, isto é, a pesquisa transdisciplinar ainda seria uma utopia (JANTSCH, 1972; NICOLESCU, 2001; PIAGET, 1972; POMBO, 2004).

\section{A ligação da ciência da informação com outras disciplinas}

Várias pesquisas da área têm apontado um relacionamento da CI com outras disciplinas numa perspectiva interdisciplinar (CHANG; HUANG, 2012; HUANG; CHANG, 2011; HUANG; CHANG, 2012; MORAES; CARELLI, 2016; PINHEIRO, 2007; PINHEIRO, 2018; TANG, 2004).

Ao longo de sua carreira, a pesquisadora Lena Vânia Ribeiro Pinheiro buscou demarcar o cenário epistemológico da área através de uma série de três diagramas/mandalas, na busca das interdisciplinaridades que reflitam as mutações ocorridas na área em cada período investigado (PINHEIRO, 2007; PINHEIRO 2018; PINHEIRO; LOUREIRO, 1995).

O centro desses diagramas/mandalas representava as disciplinas/subáreas que constituíam a área e a periferia representava as demais áreas do conhecimento com as quais a CI efetivava algum tipo relacionamento interdisciplinar. A seguir, apresenta-se o último desses diagramas/mandalas desenvolvidos pela autora que demonstra o cenário epistemológico atual da CI.

Na Figura 1, pode-se observar a última mandala publicada pela autora em 2018, em que a CI era composta por 16 subáreas (círculo intermediário). O círculo maior traz os campos do conhecimento que, numa ação interdisciplinar, poderiam contribuir com seus princípios, métodos, teorias e construtos. Por exemplo, a subárea gestão do conhecimento e inteligência competitiva, poderia efetivar assim, um relacionamento interdisciplinar com a administração e economia em suas pesquisas. 


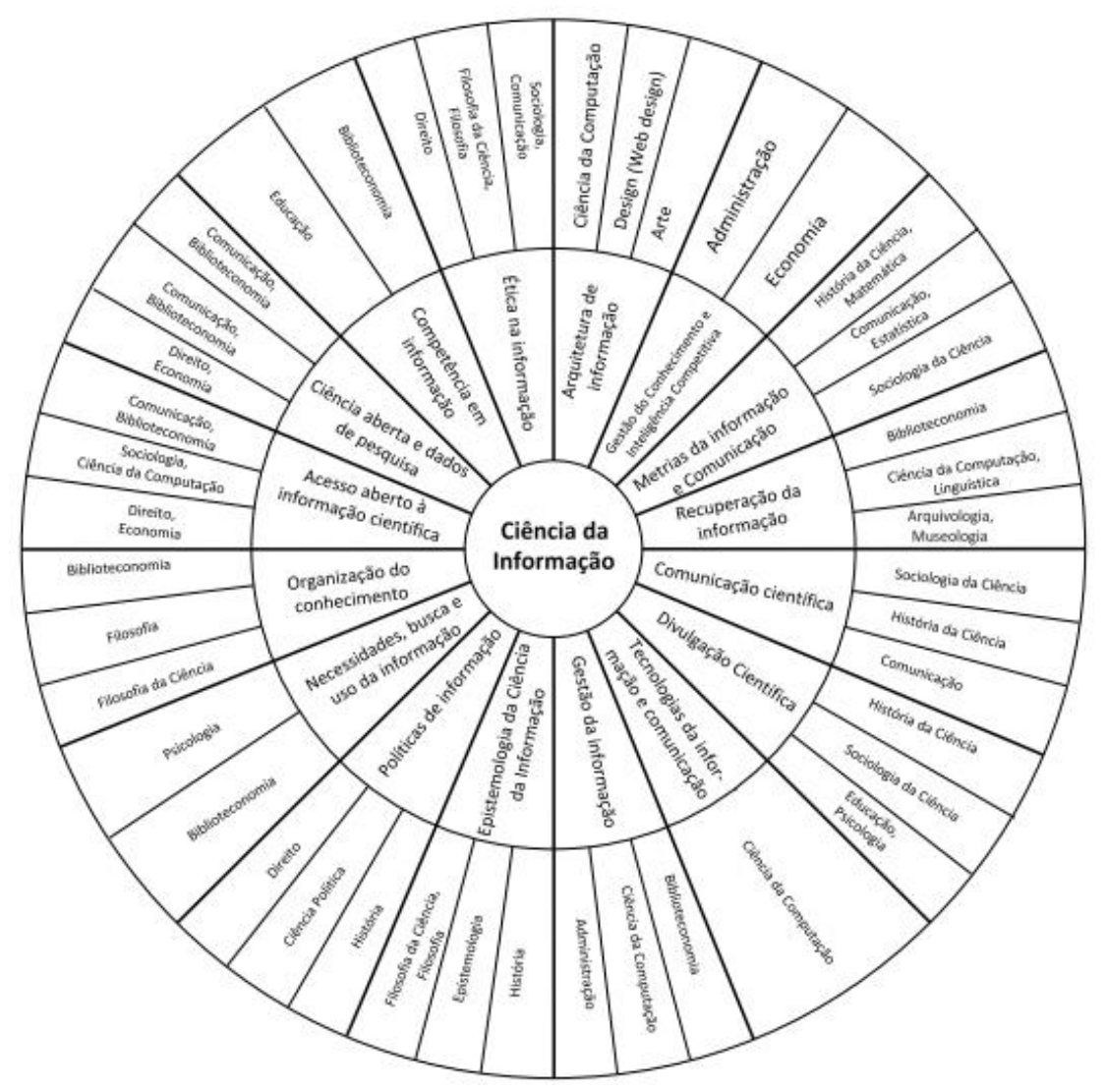

Fonte: Pinheiro (2018, p. 126).

Moraes e Carelli (2016) investigaram as relações interdisciplinares que a CI mantém com outras áreas do conhecimento. Em uma das etapas da pesquisa, empreenderam uma análise de citação de todos os artigos publicados no biênio 2011 e 2012, nos periódicos nacionais da área com estrato qualis A1 e A2, a saber: Perspectivas em Ciência da Informação, Informação e Sociedade: estudos e Transinformação. Ao todo, foram levantadas 4.316 citações válidas nos artigos selecionados.

Os resultados mostraram que a CI recorreu ao aporte teórico de outras áreas em 53\% das citações. Destas outras áreas, destacaram-se: administração (14,55\%), ciência da computação $(5,85 \%)$, sociologia $(5,26 \%)$, ciências $(4,85 \%)$, educação $(4,67 \%)$, filosofia $(3,55 \%)$, comunicação $(2,96 \%)$, psicologia $(2,07 \%)$ e letras $(1,77 \%)$. 
No cenário internacional, algumas pesquisas também tentaram identificar as possíveis áreas com as quais a CI manteve relacionamentos numa perspectiva interdisciplinar.

Tang (2004) mapeou o desenvolvimento do escopo interdisciplinar da área, através de uma investigação empírica das citações recebidas por 150 artigos da área de biblioteconomia e CI classificados na categoria de assunto ciência da informação e biblioteconomia, em três índices distintos da Web of Science (Science Citation Index, Social Science Citation Index $\boldsymbol{e}$ Arts and Humanities Science Citation Index). De acordo com os resultados, Tang (2004, p. 61, tradução nossa) comentou que o campo de biblioteconomia e CI é uma área “[...] altamente interdisciplinar que atrai o interesse de uma variedade de disciplinas das ciências, das ciências sociais e humanidades". Logo adiante, o autor conclui seu raciocínio dizendo que "[...] o campo tem abundância de substância intelectual que são de interesse para várias extras disciplinas incluindo ciência da computação, comunicação, educação e administração" (TANG, 2004, p. 61, tradução nossa).

Entre os anos de 2011 e 2012, os autores Huang e Chang publicaram uma trilogia de artigos científicos que discutiu a interdisciplinaridade na biblioteconomia e CI em diferentes aspectos.

No primeiro artigo, Huang e Chang (2011) elaboraram um estudo no qual eles utilizaram dois métodos bibliográficos (citação direta e análise de co-autoria), com o objetivo de investigar as mudanças interdisciplinares no campo da CI entre 1978 e 2007. Como corpo empírico, foram utilizados 770 artigos de CI publicados entre 1978 e 2007, em cinco distintos periódicos indexados na categoria de assunto information science and library science (ciência da informação e biblioteconomia) no Journal Citation Reports (JCR) de 2008.

No que diz respeito às principais áreas interdisciplinares com a CI, os resultados revelaram que dentre as cinco áreas com mais relações interdisciplinares com a CI apontadas nos dois métodos bibliográficos, quatro coincidiram, sendo as três primeiras as mesmas: biblioteconomia e ciência da informação, ciências gerais e ciência da computação. A outra disciplina em comum foi medicina, que ficou na quinta colocação nos dois métodos. A quarta 
colocada na análise de citação foi engenharia enquanto, na análise de co-autoria, a quarta colocada foi administração.

No segundo artigo, Huang e Chang (2012) compararam, através de uma análise de citação direta, as características interdisciplinares entre a biblioteconomia e a CI entre 1978 e 2007. A amostra da pesquisa foi constituída por 766 artigos de cinco periódicos de biblioteconomia e mais 770 artigos de cinco periódicos de CI.

Como primeiro resultado dessa pesquisa, os autores apontaram a inconsistência entre o core de disciplinas com as quais cada campo trabalha. Nos artigos do campo da biblioteconomia, as cinco disciplinas mais citadas foram: biblioteconomia e CI (65,61\%), educação (5,65\%), administração (5,32\%), sociologia $(3,70 \%)$ e psicologia $(2,30 \%)$. No campo da CI, as principais disciplinas foram: biblioteconomia e CI (49,5\%), ciências gerais (11,75\%), ciência da computação $(5,53 \%)$, tecnologia $(4,39 \%)$, medicina $(3,81 \%)$. Esses resultados levaram Huang e Chang (2012) a duas conclusões: a primeira é que o campo da biblioteconomia depende mais dos conhecimentos produzidos na disciplina biblioteconomia e CI do que o campo da CI. A segunda é que pesquisadores da biblioteconomia tendem a citar mais publicações de ciências sociais, enquanto pesquisadores da CI tendem a citar mais publicações das ciências naturais.

No último artigo, Chang e Huang (2012) utilizaram três métodos bibliográficos (citação direta, acoplamento bibliográfico e análise de co-autoria) com o objetivo de investigar as mudanças interdisciplinares no campo da biblioteconomia e CI entre 1978 e 2007 . Como corpo empírico, foram utilizados 1.536 artigos de biblioteconomia e CI publicados entre 1978 e 2007 em 10 periódicos distintos da área.

Ao todo, nos três testes bibliométricos executados, foi verificada a influência de 30 disciplinas diferentes na biblioteconomia e CI, mas somente oito disciplinas distintas estavam entre as cinco mais citadas em cada teste feito. Estas disciplinas foram: biblioteconomia e CI, ciências em geral, administração, ciência da computação, educação, sociologia, medicina e economia. Porém somente 
biblioteconomia e CI, ciências em geral e ciência da computação foram citadas ao mesmo tempo entre as cinco disciplinas mais citadas nos três testes elaborados.

Outra análise dos autores revelou que somente seis disciplinas, além da própria biblioteconomia e CI, tiveram índices de citações acima de 1\%, ao mesmo tempo. Nos três testes efetuados, estas disciplinas foram: ciências gerais, administração, ciência da computação, engenharia, psicologia e ciências sociais em geral. Os autores concluíram que um grande número de disciplinas exerce um baixo grau de influência na biblioteconomia e CI, uma vez que mais da metade das disciplinas tiveram representatividade de menos de $1 \%$ das citações em algum dos três testes bibliométricos executados.

\section{Metodologia}

O objetivo geral proposto é pesquisar, para além dos movimentos que a CI faz em direção às outras disciplinas, os movimentos de outras disciplinas em direção à CI e se esses movimentos se concretizam numa perspectiva de integração. Para alcançar este objetivo, problematizado por Gomes (2001) e Santos Neto et al. (2017), bem como os objetivos secundários estabelecidos, este artigo teve seu percurso metodológico dividido em duas etapas.

Cabe explicar que o corrente estudo não se utiliza de metodologias adotadas para investigar a interdisciplinaridade da área presentes nos trabalhos citados, como análise de citações (metodologia utilizada por CHANG; HUANG (2012); HUANG; CHANG (2011); MORAES; CARELLI (2016); TANG (2004)) ou análise de co-autoria (metodologia adotada por HUANG; CHANG (2011); Chang e Huang (2012), uma vez que esses métodos, na concepção dos autores, conseguem no máximo apontar que houve uma correlação entre as áreas, mas não permitem determinar o alcance da correlação.

\subsection{Primeira etapa}

Para identificar se há outras áreas que recorrem às descobertas da CI internacional para sanar suas inquietações/problemas e quais são elas, foram levantados 
relevantes periódicos internacionais que se dedicam a publicar exclusivamente pesquisas realizadas dentro do escopo de interesse da área indexados na Web of Science.

Para identificação dos principais periódicos internacionais em CI, foi feita uma consulta nos índices Social Sciences Citation Index (SSCI) e Science Citation Index Expanded (SCIE) da base JCR por todos os periódicos indexados exclusivamente por esses índices na categoria Information Science \& Library Science (ciência da informação e biblioteconomia) com fator de impacto igual ou maior do que 1 (ver Quadro 1).

Quadro 1 - Periódicos de maior fator de impacto classificados exclusivamente na categoria Information Science \& Library Science indexados nos índices SSCI e SCIE do JCR

\begin{tabular}{|c|c|c|}
\hline Rank & Título do Periódico & Fator de impacto \\
\hline 1 & Information Systems Journal & 4.122 \\
\hline 2 & Government Information Quarterly & 4.090 \\
\hline 3 & International Journal of Information Management & 3.872 \\
\hline 4 & Telematics and Informatics & 3.398 \\
\hline 5 & Research Evaluation & 2.312 \\
\hline 6 & Information Development & 1.691 \\
\hline 7 & Journal of the Medical Library Association & 1.638 \\
\hline 8 & Information Society & 1.558 \\
\hline 9 & College \& Research Libraries & 1.515 \\
\hline 10 & Aslib Journal of Information Management & 1.514 \\
\hline 11 & Information Technology \& People & 1.339 \\
\hline 12 & Information Technology for Development & 1.333 \\
\hline 13 & Learned Publishing & 1.333 \\
\hline 14 & Portal-Libraries and the Academy & 1.290 \\
\hline 15 & Journal of Academic Librarianship & 1.287 \\
\hline 16 & Library \& Information Science Research & 1.185 \\
\hline 17 & Journal of Global Information Technology Management & 1.167 \\
\hline 18 & Profesional de la Informacion & 1.063 \\
\hline 19 & Journal of Librarianship and Information Science & 1.019 \\
\hline
\end{tabular}

Fonte: Elaborado pelos autores (2018). 
Dentre os 19 periódicos classificados somente na categoria ciência da informação e biblioteconomia pelo JCR, foram selecionados para compor o corpus desta pesquisa aqueles que apresentavam em seu título o nome da área, isto é, information science (ciência da informação). Esses periódicos foram escolhidos por pressupor que eles publicassem e, por consequência, representassem todas as temáticas de pesquisa da área. Verificou-se que apenas dois destes 19 periódicos apresentavam esse requisito (Library \& Information Science Research e Journal of Librarianship and Information Science). Porém, com o objetivo de aumentar a representatividade um terceiro periódico foi eleito aleatoriamente, dentre os demais 17 periódicos. O periódico Learned Publishing foi escolhido por publicar, segundo o julgamento dos autores, pesquisas que abordassem todas as temáticas de interesse da área.

Para a avaliação do uso do conhecimento produzido pela CI internacional por pesquisadores das demais áreas científicas foi elaborada uma análise retrospectiva dos anos de 1997 até 2016, a qual possibilitou traçar um panorama histórico-evolutivo da interação de outras disciplinas com a CI estrangeira durante esse período de 20 anos.

Na seleção das citações à CI internacional, foi efetuada inicialmente uma busca na base de dados Web of Science, por todos os artigos publicados entre 1997 e 2016 pelos três periódicos internacionais de CI selecionados para análise. Após esse levantamento, foi investigado se existiam artigos que citavam os artigos publicados entre 1997 e 2016 pelos três periódicos internacionais de CI analisados e a quais áreas do conhecimento pertenciam.

Para análise e determinação das áreas que estavam utilizando o conhecimento produzido pelo campo na esfera internacional foi considerada a categoria do periódico do documento citante na Web of Science. Caso o periódico fosse classificado em mais de uma categoria de forma simultânea pela Web of Science, todas essas categorias foram consideradas e computadas.

Por ser a classificação adotada pela Web of Science muito específica, também foi realizado um trabalho de conversão dessas áreas temáticas para as áreas de conhecimento estabelecidas pelo Conselho Nacional de 
Desenvolvimento Científico e Tecnológico (CNPq), conforme anexo utilizado por Fernandes (2019).

\subsection{Segunda etapa}

Na segunda etapa foi avaliado o nível de interação (uni, multi, inter ou transdisciplinar) estabelecido nos documentos citantes pertencentes a áreas externas à CI com a CI. Tal avaliação foi feita através de análise quanti/qualitativa de uma amostra não-probabilística, com seleção por conveniência, de $15 \%$ das 2.124 citações de áreas externas concedidas à literatura produzida pelo campo na esfera internacional, identificados na primeira etapa, ou seja, 319 citações.

Como a Web of Science não é uma base de texto completo, justifica-se a seleção de uma amostra não-probabilística uma vez que não se teria acesso a uma quantidade expressiva de citações que porventura seriam sorteadas aleatoriamente para compor a amostra. Tal ocorrência prejudicaria o rigor que deve ser adotado numa pesquisa com amostra probabilística, invalidando assim seus resultados.

A seleção dos trabalhos que constituíram a amostra da segunda etapa ocorreu de acordo com a seguinte rotina demonstrada no fluxograma da Figura 2. 
Figura 2 - Fluxograma da rotina para seleção na Web of Science da amostra dos trabalhos das citações a serem analisados na segunda etapa

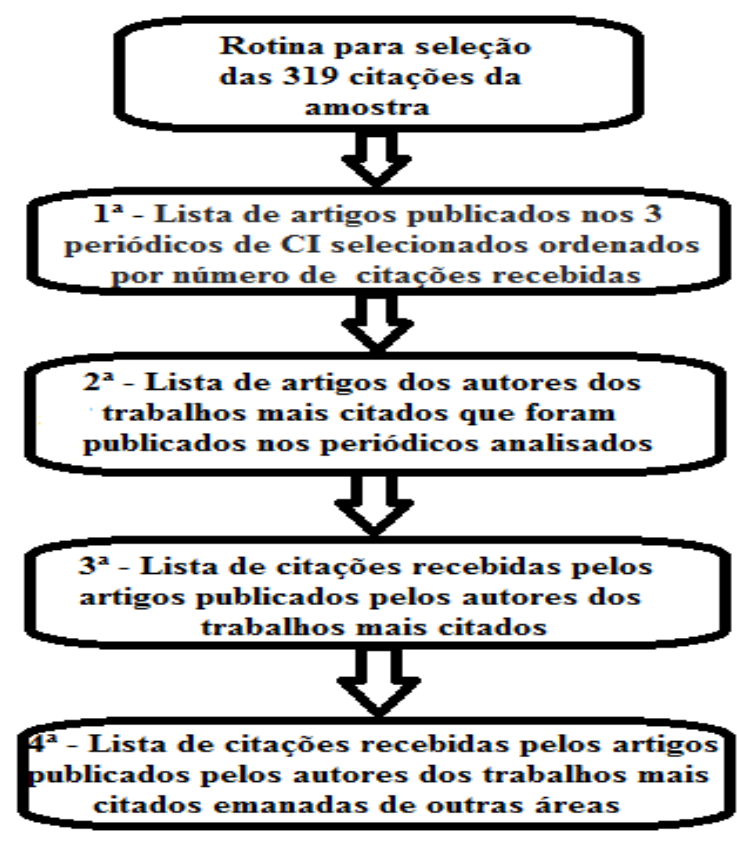

Fonte: Elaborada pelos autores (2020).

A primeira rotina foi listar todos os artigos publicados entre 1997 e 2016, pelos respectivos periódicos estrangeiros de CI identificada na primeira etapa e ordená-la por número de citações recebidas através de opção fornecida pela Web of Science.

A rotina seguinte foi efetuar uma busca na Web of Science de quantos artigos cada autor internacional reconhecidamente da área de CI, dos respectivos artigos mais citados, havia publicado no período de 1997 a 2016 nos três periódicos analisados.

A seguir levantou-se quantas citações cada autor dos artigos mais citados tinha recebido em todos os artigos publicados por ele nos periódicos e no período analisado.

A última rotina se constituiu do levantamento de quantas e quais dessas eram citações oriundas de documentos publicados por periódicos de outras áreas.

Seguiu-se essa rotina até completar a quantidade de amostras desejadas, ou seja, 319 citações de outras áreas ao do conhecimento produzido pela área de CI internacional. $\mathrm{Na}$ seleção dessa amostra não foram contabilizadas/consideradas as citações de outras áreas concedidas ao autor 
internacional de CI que mais citações de outra(s) área(s) havia recebido. Essa exclusão teve o objetivo de eliminar algum viés e também distribuir a amostra por uma quantidade maior de autores. Também não foram consideradas as citações a que não se pode ter acesso ao texto completo.

Ainda durante a seleção das citações da amostra pode ter ocorrido a inclusão de um mesmo trabalho no seu somatório final, assim como pode ter ocorrido no somatório final da população. Essa duplicidade é plausível, considerando que um mesmo trabalho pode ter citado simultaneamente artigos distintos dos periódicos de CI analisados. Além disso, a ferramenta utilizada nesse levantamento, a Web of Science, não oferece mecanismos para identificar e filtrar a ocorrência relatada anteriormente.

O objetivo desta etapa foi avaliar o nível de interação disciplinar com a CI, estabelecido pelos documentos das citações de outras áreas ao conhecimento produzido pela CI internacional. Para isso, os autores elaboraram uma série de pressupostos propostos com base na literatura e nos significados dos três tipos de interação (multi, inter e transdisciplinar), discutidos nesse trabalho.

$\mathrm{O}$ primeiro pressuposto considerou que as citações à literatura de CI pela própria CI, foram construídas sem nenhuma relação disciplinar. Nesta condição, apenas pesquisador(es) da própria disciplina utilizou(zaram)-se do arcabouço teórico, metodológico e aplicado produzido pelo campo com o objetivo de avançar no conhecimento da área, não ocorrendo em nenhum desses casos uma relação mínima que seja entre disciplinas distintas de modo a ensejar algum outro tipo de relação disciplinar, seja ela multi, inter ou transdisciplinar.

Sendo consideradas como citações provenientes de trabalhos unidisciplinares, essa cota de citações concedidas à CI pela própria área não foi objeto de análise por não estar contemplada nos objetivos da pesquisa.

O segundo pressuposto foi de que todas as citações à literatura de CI internacional pertencentes às disciplinas externas poderiam ter estabelecido algum tipo de relação disciplinar com a área.

O terceiro pressuposto diz respeito à pesquisa transdisciplinar que a partir dos parâmetros teórico-conceituais discutidos no referencial teórico seria uma forma utópica de relação disciplinar, ainda distante de ser atingida nos moldes das 
atuais estruturas das comunidades científicas, dos regimes pedagógicos e da organização da instituição escolar. Por isso, foi considerada como praticamente impossível de ser efetivada no conjunto de citações à literatura de CI internacional analisada e, caso ocorresse, sua representatividade não seria significativa.

Por fim, a pesquisa adotou o pressuposto de que para que possa haver relação interdisciplinar com a CI, as citações concedidas a área devam ter sido provenientes de trabalhos produzidos de forma coletiva entre pesquisador(es) de outra(s) disciplina(s) com pesquisador(es) da CI (seja (m) ele (s) de formação ou atuação), ou sejam citações provenientes de trabalhos individuais desenvolvidos por investigador formado em CI, mas com atuação em outra área, ou por pesquisador formado em outra área, mas com atuação em CI.

Numa análise preliminar dos trabalhos das 319 citações da amostra, foram levantados dados relativos aos seguintes fatores considerados como contributivos para efetivação de relações disciplinares: número de autores, formação dos autores e área de atuação. Os dados foram identificados no campo autoria dos trabalhos e, também, em buscas na internet em sites como: Research Gate, Linkedin, ORCID, sites das instituições de ensino dos autores, sites pessoais dos pesquisadores e buscadores da internet.

As classificações das formações e áreas de atuação dos autores das citações de outras áreas ao conhecimento da CI internacional foram divididas em cinco possibilidades: (1) $\mathrm{CI}^{1}$; (2) outra área exceto a CI; (3) outra área mais a CI; (4) outras áreas mais a CI; (5) outras áreas exceto a CI.

Os fatores número, formação e área de atuação dos autores foram combinados para determinar o nível de interação/relação verificado de acordo com os pressupostos assumidos.

Após análise cruzada desses fatores (ver Quadro 2), foram consideradas citações:

a) unidisciplinares, sem interação entre áreas, todas as citações provenientes de documentos produzidos somente por:

— um ou mais autores categorizados com formação e área de atuação concomitantes somente em CI (1). 
b) multidisciplinares, todas as citações oriundas de documentos produzidos por:

- um autor categorizado com formação e área de atuação em outra(s) área(s) do conhecimento que não a CI. Por exemplo: um autor com formação e atuação em enfermagem ou com formação em enfermagem e medicina e atuação em medicina (2);

— dois ou mais autores categorizados com formação e área de atuação em outra área do conhecimento que não a CI. Por exemplo: dois autores com formação e atuação em ciências contábeis (3);

— dois ou mais autores categorizados com formação e área de atuação em outras áreas do conhecimento que não a CI. Por exemplo: um autor com formação e atuação em ciência contábil e outro autor com formação e atuação em administração (4).

c) com propriedades indicativas de relações interdisciplinares todas as citações da amostra oriundas de documentos produzidos por:

- um autor categorizado com formação em outra(s) área(s) do conhecimento mais CI e com área de atuação somente em outra(s) áreas(s) do conhecimento ou em outra(s) área(s) do conhecimento mais CI ou somente CI. Por exemplo: um autor com formação em CI e engenharia de produção e área de atuação em engenharia de produção ou área de atuação em engenharia de produção e CI ou área de atuação somente em CI (5);

- um autor categorizado com formação em outra(s) área(s) do conhecimento que não a CI e área de atuação em outras áreas e CI ou somente CI. Por exemplo: um autor com formação em história e filosofia, mas com área de atuação em história e CI ou com área de atuação somente em CI (6);

— um autor categorizado com formação em CI e área de atuação em outra(s) área(s) ou outra(s) área(s) e CI. Por exemplo: um autor com formação em CI, mas com área de atuação em sistemas de informação ou área de atuação em sistemas de informação e CI (7); 
— dois ou mais autores categorizados com formação em outra(s) área(s) do conhecimento e pelo menos um deles mais CI e com área de atuação em outra(s) área(s) ou outra(s) área(s) e CI ou somente CI. Por exemplo: dois autores com formação em história e mais um autor também com formação em CI e os três autores com área de atuação em história ou dois autores com área de atuação em história mais um autor com área de atuação em CI ou os três autores com área de atuação em CI (8);

— dois ou mais autores categorizados com formação em outra(s) área(s) do conhecimento e com área de atuação em outra(s) área(s) do conhecimento e pelo menos um deles mais CI ou com área de atuação somente em CI. Por exemplo: três autores, um com formação em engenharia civil e dois com formação em matemática e dois autores com área de atuação em matemática e outro com área de atuação em CI ou os três com área de atuação somente em CI (9);

— dois ou mais autores categorizados com formação em CI e área de atuação em outra(s) área(s) ou outra(s) área(s) e CI. Por exemplo: dois autores com formação em CI e os dois autores com área de atuação em sistemas de informação ou um autor com área de atuação em sistema de informação e CI e o outro em sistema de informação ou um autor com área de atuação em CI e o outro com área de atuação em sistema de informação (10). 
Quadro 2 - Tipo de relação verificada na análise quantitativa da amostra das citações à literatura de CI internacional a partir dos pressupostos estabelecidos

\begin{tabular}{|c|c|c|c|}
\hline \multirow{2}{*}{ Tipo de relação verificada } & \multicolumn{3}{|c|}{ Fatores combinados } \\
\hline & $\begin{array}{l}\text { Número de } \\
\text { Autores }\end{array}$ & $\begin{array}{c}\text { Formação dos } \\
\text { autores }\end{array}$ & Atuação dos autores \\
\hline Unidisciplinares & 1 ou mais & (e) CI (1) & (e) CI (1) \\
\hline \multirow[t]{3}{*}{ Multidisciplinares } & 1 & $\begin{array}{ll}(\mathrm{e}) & \text { Outra(s) } \\
\text { área(s) } & (2)\end{array}$ & (e) Outra(s) área(s) (2) \\
\hline & 2 ou mais & $\begin{array}{l}(\mathrm{e}) \quad \text { Outra } \\
\text { mesma área (3) }\end{array}$ & (e) Outra mesma área (3) \\
\hline & 2 ou mais & $\begin{array}{l}\text { (e) Outras áreas } \\
\text { (4) }\end{array}$ & (e) Outras áreas (4) \\
\hline \multirow[t]{6}{*}{$\begin{array}{l}\text { Propriedades indicativas de } \\
\text { relações interdisciplinares }\end{array}$} & 1 & $\begin{array}{l}\text { (e) } \quad \text { Outra(s) } \\
\text { área(s) e CI (5) }\end{array}$ & $\begin{array}{l}\text { (e) Somente em outra(s) } \\
\text { área(s) ou outra(s) área(s) e } \\
\text { CI ou somente CI (5) }\end{array}$ \\
\hline & 1 & $\begin{array}{l}\text { (e) Outra(s) } \\
\text { área(s) (6) }\end{array}$ & $\begin{array}{l}\text { (e) Outra(s) área(s) e CI ou } \\
\text { somente CI (6) }\end{array}$ \\
\hline & 1 & (e) CI (7) & $\begin{array}{l}\text { (e) Outra(s) área(s) ou } \\
\text { outra(s) área(s) e CI (7) }\end{array}$ \\
\hline & 2 ou mais & $\begin{array}{l}\text { (e) } \quad \text { Outra(s) } \\
\text { área(s) e CI (8) }\end{array}$ & $\begin{array}{l}\text { (e) Somente em outra(s) } \\
\text { área(s) ou outra(s) área(s) e } \\
\text { CI ou somente CI (8) }\end{array}$ \\
\hline & 2 ou mais & $\begin{array}{l}\text { (e) Outra(s) } \\
\text { área(s) (9) }\end{array}$ & $\begin{array}{l}\text { (e) Outra(s) área(s) e CI ou } \\
\text { somente CI (9) }\end{array}$ \\
\hline & 2 ou mais & (e) CI (10) & $\begin{array}{l}\text { (e) Outra(s) área(s) ou outras } \\
\text { áreas e CI (10) }\end{array}$ \\
\hline
\end{tabular}

Fonte: Elaborado pelos autores (2020).

Para determinar o real tipo de relação estabelecida entre a área de CI e o conjunto de trabalhos das citações da amostra que se enquadraram no grupo de trabalhos classificados, com propriedades indicativas de relações interdisciplinares, foi realizada uma análise qualitativa através da leitura integral do texto.

$\mathrm{Na}$ análise qualitativa foram avaliadas teorias/referências utilizadas e resultados obtidos, que são outros fatores considerados por Bicalho (2009) como contributivos para ocorrência de relações interdisciplinares. Para se determinar o tipo de relacionamento/interação verificado na análise qualitativa apoiou-se no guia adaptado de Bicalho (2009). Ver Quadro 3. 
Quadro 3 - Guia adaptado de Bicalho (2009) com as propriedades avaliadas na análise qualitativa indicativas de relações interdisciplinares

\begin{tabular}{|c|c|}
\hline Propriedades & Ponderação \\
\hline \multicolumn{2}{|l|}{ 1. Formação acadêmica dos autores } \\
\hline Autoria única com formação única: outra área & 0 \\
\hline Autoria única com formação única: CI & 0 \\
\hline Autoria única com formação múltipla: outras áreas exceto CI & 0 \\
\hline Autoria única com formação múltipla: outra(s) área(s) e CI & 3 \\
\hline Autoria múltipla com formação única: outra área & 0 \\
\hline Autoria múltipla com formação única: CI & 0 \\
\hline Autoria múltipla com formação múltipla: outras áreas & 0 \\
\hline Autoria múltipla com formação múltipla: outra(s) área(s) e CI & 3 \\
\hline \multicolumn{2}{|l|}{ 2. Área de atuação dos autores } \\
\hline Atuação estrita em CI & 0 \\
\hline Atuação estrita em outra área & 0 \\
\hline Atuação estrita em outras áreas & 0 \\
\hline Atuações em mais de uma área: outra(s) área(s) e CI & 3 \\
\hline \multicolumn{2}{|l|}{ 3. Embasamento conceitual/metodologia } \\
\hline Exclusivamente de outra(s) área(s) & 0 \\
\hline Exclusivamente da CI & 0 \\
\hline Com predominância de teorias/técnicas da CI & 1 \\
\hline Com predominância de teorias/técnicas outra(s) área(s) & 1 \\
\hline Compartilhamento de teorias/técnicas das áreas (CI e outra(s) área(s)) & 3 \\
\hline \multicolumn{2}{|l|}{ 4. Resultados apresentados } \\
\hline Dirigidos somente a outra(s) área(s) & 0 \\
\hline Dirigidos somente à CI & 0 \\
\hline Dirigidos predominantemente a outra(s) área(s) & 1 \\
\hline Dirigidos predominantemente à CI & 1 \\
\hline Dirigidos à CI e a outra(s) área(s) & 3 \\
\hline
\end{tabular}

Fonte: Adaptado de Bicalho (2009).

No guia apresentado no Quadro 3, foram listados todos os fatores avaliados, nos trabalhos das citações de outras áreas ao conhecimento produzido pela CI com propriedades indicativas de relações interdisciplinares, bem como uma nota/peso a ser atribuída para cada fator, de acordo com a realidade observada na análise. Para o estabelecimento dessas notas, foram consideradas, a partir da literatura estudada, as possibilidades de um trabalho ter sido construído a partir de uma relação interdisciplinar, sendo zero para trabalhos sem nenhuma 
chance, um para trabalhos com alguma chance e três para trabalhos com maiores chances.

Após a leitura de cada trabalho foi feita a transcrição das notas de cada fator avaliado para o guia apresentado no Quadro 3. Ciente de que provavelmente nenhum trabalho reuniria, separadamente, todos os fatores elencados no guia, conforme observado por Bicalho (2009), somente foram consideradas citações provenientes de trabalhos construídos à base de uma relação interdisciplinar entre as outras disciplinas e a CI, aquelas que obtiveram, no mínimo, uma nota três na soma da análise das duas primeiras variáveis (formação acadêmica dos autores e área de atuação dos autores) e uma nota quatro na soma da análise das duas últimas variáveis analisadas (embasamento conceitual/metodologia e resultados apresentados).

Nos casos em que a nota na análise das duas primeiras variáveis fosse zero, mas com indicação de autoria com formação em CI e atuação em outra(s) área(s) de maneira concomitante ou formação em outra(s) área(s) e atuação em CI de maneira concomitante e ainda uma dessas áreas externas fosse uma das beneficiadas com os resultados além da CI, o trabalho foi considerado interdisciplinar, se obtivesse uma nota quatro na soma da análise das duas últimas variáveis analisadas.

A utilização do guia adaptado de Bicalho (2009) nesta análise visou avaliar se o nível de integração entre teorias e metodologias das disciplinas em conexão possibilitava um enriquecimento mútuo, configurando assim a ocorrência de uma pesquisa interdisciplinar.

\section{Apresentação e análise dos Resultados}

\subsection{Primeira etapa}

Na análise das citações recebidas durante o período investigado (1997 a 2016) pelos artigos da área publicados entre 1997 a 2016 nos periódicos internacionais de CI investigados (ver Tabela 1), verificou-se a ocorrência de 5.097 citações na Web of Science. Destas, 2.973 (58,3\%) foram concedidas pela própria área. As demais citações foram concedidas por trabalhos das seguintes áreas: educação 
(6,6\%), ciência da computação $(5,7 \%)$, psicologia $(4,1 \%)$, administração $(2,5 \%)$, medicina $(2,4 \%)$, estudos multidisciplinares afins $(1,5 \%)$, saúde coletiva $(1,4 \%)$, comunicação $(1,3 \%)$, ciências sociais $(1,2 \%)$ e demais áreas $(15,0 \%)$. Nos casos em que não foi possível determinar uma área específica foi utilizada a classificação pela grande área como: ciências sociais, ciências da saúde, engenharias, ciências humanas e ciências biológicas.

Constatou-se também que um pequeno número de áreas tem uma maior relação com a CI internacional e um grande número de áreas tem uma menor relação com a CI internacional. Apenas cinco áreas externas foram responsáveis por $21,2 \%$ das citações concedidas à CI no cenário internacional, enquanto as demais 68 áreas externas foram responsáveis por 20,5\% das citações concedidas à CI internacional.

Outra descoberta que chamou atenção foi o grande número de áreas externas que citaram o conhecimento produzido pelo campo no cenário internacional. De acordo com a tabela de áreas do conhecimento adotada para classificação das áreas, existem 103 áreas externas à CI. Dessas, 68 (66\%) utilizaram o conhecimento produzido pela CI internacional nos 20 anos analisados. Nesta análise já foram descontadas as citações classificadas pelas grandes áreas.

Tabela 1 - Área do conhecimento dos trabalhos das citações concedidas à literatura de CI internacional no período de 1997 a 2016

\begin{tabular}{lrr}
\hline \multicolumn{1}{c}{ Área de conhecimento da citação } & $\begin{array}{c}\text { Número de citaçães } \\
\text { concedidas }\end{array}$ & \% \\
Ciência da informação & 2973 & $58,3 \%$ \\
Educação & 335 & $6,6 \%$ \\
Ciência da computação & 291 & $5,7 \%$ \\
Psicologia & 209 & $4,1 \%$ \\
Administração & 125 & $2,5 \%$ \\
Medicina & 123 & $2,4 \%$ \\
Estudos multidisciplinares afins & 78 & $1,5 \%$ \\
Saúde coletiva & 69 & $1,4 \%$ \\
Comunicação & 65 & $1,3 \%$ \\
Ciências sociais & 61 & $1,2 \%$ \\
Outras áreas & 768 & $15,0 \%$ \\
Total & $\mathbf{5 . 0 9 7}$ & $\mathbf{1 0 0 \%}$ \\
\hline
\end{tabular}

Fonte: Elaborado pelos autores (2020). 
A seguir serão apresentadas as análises das citações por quinquênios. Os artigos de CI publicados entre 1997 e 2001 nos periódicos internacionais investigados receberam um total de 117 citações na Web of Science no período de 1997 a 2001 (primeiro quinquênio), conforme Tabela 2. Destas, 79 (67,5\%) foram concedidas por trabalhos da própria área do conhecimento. As demais citações foram concedidas por trabalhos das seguintes áreas: psicologia (12,0\%), educação (7,7\%), ciência da computação (4,3\%), engenharia elétrica $(1,7 \%)$ e demais áreas $(6,8 \%)$.

Tabela 2 - Área de conhecimento dos trabalhos das citações concedidas à literatura de CI internacional no período de 1997 a 2001

\begin{tabular}{lrr}
\hline Área de conhecimento da citação & $\begin{array}{c}\text { Número de citações } \\
\text { concedidas }\end{array}$ & $\%$ \\
Ciência da informação & 79 & $67,5 \%$ \\
Psicologia & 14 & $12,0 \%$ \\
Educação & 9 & $7,7 \%$ \\
Ciência da computação & 5 & $4,3 \%$ \\
Engenharia elétrica & 2 & $1,7 \%$ \\
Outras áreas & 8 & $6,8 \%$ \\
Total & $\mathbf{1 1 7}$ & $\mathbf{1 0 0 , 0 \%}$ \\
\hline
\end{tabular}

Fonte: Elaborado pelos autores (2020).

Os artigos de CI publicados entre 1997 e 2006 nos periódicos internacionais investigados receberam um total de 592 citações na Web of Science no período de 2002 a 2006 (segundo quinquênio), conforme Tabela 3. Em trabalhos de 15 citações não foi possível estabelecer uma área e, por esse motivo, eles foram classificados pela grande área. Das 592 citações recebidas, 399 $(67,4 \%)$ foram concedidas por trabalhos da própria área do conhecimento. As demais citações foram concedidas por trabalhos das seguintes áreas: ciência da computação (6,8\%), educação (3,9\%), psicologia (3,5\%), medicina $(1,5 \%)$, administração e engenharia de produção (1,4\% cada), ciências da saúde $(1,2 \%)$, comunicação e ecologia $(1,0 \%)$ e demais áreas $(10,9 \%)$. 
Tabela 3 - Área de conhecimento dos trabalhos das citações concedidas à literatura de CI internacional no período de 2002 a 2006

\begin{tabular}{lrr}
\hline Área de conhecimento da citação & $\begin{array}{c}\text { Número de citações } \\
\text { concedidas }\end{array}$ & \% \\
Ciência da informação & 399 & $67,4 \%$ \\
Ciência da computação & 40 & $6,8 \%$ \\
Educação & 23 & $3,9 \%$ \\
Psicologia & 21 & $3,5 \%$ \\
Medicina & 9 & $1,5 \%$ \\
Administração & 8 & $1,4 \%$ \\
Engenharia de produção & 8 & $1,4 \%$ \\
Ciências da saúde & 7 & $1,2 \%$ \\
Comunicação & 6 & $1,0 \%$ \\
Ecologia & 6 & $1,0 \%$ \\
Outras áreas & 65 & $10,9 \%$ \\
Total & $\mathbf{5 9 2}$ & $\mathbf{1 0 0 , 0 \%}$ \\
\hline
\end{tabular}

Fonte: Elaborado pelos autores (2020).

Os artigos de CI publicados entre 1997 e 2011 nos periódicos internacionais investigados receberam um total de 1.368 citações na Web of Science no período de 2007 a 2011 (terceiro quinquênio), conforme Tabela 4. Em trabalhos de 57 citações não foi possível estabelecer uma área e, por esse motivo, eles foram classificados pela grande área. Das 1.368 citações recebidas, 832 $(60,8 \%)$ foram concedidas por trabalhos da própria área do conhecimento. As demais citações foram concedidas por trabalhos das seguintes áreas: ciência da computação $(6,2 \%)$, educação $(5,5 \%)$, psicologia $(3,1 \%)$, administração $(2,6 \%)$, medicina e saúde coletiva (2,0\% cada), ciências da saúde $(1,8 \%)$, engenharias $(1,2 \%)$, estudos multidisciplinares afins $(1,1 \%)$ e as demais áreas $(13,7 \%)$. 
Tabela 4 - Área de conhecimento dos trabalhos das citações concedidas à literatura de CI internacional no período de 2007 a 2011

\begin{tabular}{lrr}
\hline \multicolumn{1}{c}{ Área de conhecimento da citação } & $\begin{array}{c}\text { Número de citações } \\
\text { concedidas }\end{array}$ & $\%$ \\
Ciência da informação & 832 & $60,8 \%$ \\
Ciência da computação & 85 & $6,2 \%$ \\
Educação & 75 & $5,5 \%$ \\
Psicologia & 43 & $3,1 \%$ \\
Administração & 35 & $2,6 \%$ \\
Medicina & 27 & $2,0 \%$ \\
Saúde coletiva & 27 & $2,0 \%$ \\
Ciências da saúde & 25 & $1,8 \%$ \\
Engenharias & 16 & $1,2 \%$ \\
Estudos multidisciplinares afins & 15 & $1,1 \%$ \\
Outras áreas & 188 & $13,7 \%$ \\
Total & $\mathbf{1 3 6 8}$ & $\mathbf{1 0 0 \%}$ \\
\hline
\end{tabular}

Fonte: Elaborado pelos autores (2020).

Os artigos de CI publicados entre 1997 e 2016 nos periódicos internacionais investigados receberam um total de 3.020 citações na Web of Science no período de 2012 a 2016 (quarto quinquênio), conforme Tabela 5. Em trabalhos de 112 citações não foi possível estabelecer uma área e, por esse motivo, eles foram classificados pela grande área. Das 3.020 citações, $1.663(55,1 \%)$ foram concedidas por trabalhos da própria área do conhecimento. As demais citações foram concedidas por trabalhos das seguintes áreas do conhecimento: educação (7,5\%), ciência da computação (5,3\%), psicologia (4,3\%), medicina (2,8\%), administração (2,7\%), estudos multidisciplinares afins (2,0\%), comunicação e ciências sociais $(1,5 \%$ cada), linguística $(1,4 \%)$ e as demais áreas $(15,9 \%)$. 
Tabela 5 - Área do conhecimento dos trabalhos das citações concedidas à literatura de CI internacional no período de 2012 a 2016

\begin{tabular}{lrr}
\hline \multicolumn{1}{c}{ Área de conhecimento da citação } & $\begin{array}{c}\text { Número de citações } \\
\text { concedidas }\end{array}$ & \% \\
Ciência da informação & 1663 & $55,1 \%$ \\
Educação & 228 & $7,5 \%$ \\
Ciência da computação & 161 & $5,3 \%$ \\
Psicologia & 131 & $4,3 \%$ \\
Medicina & 86 & $2,8 \%$ \\
Administração & 81 & $2,7 \%$ \\
Estudos multidisciplinares afins & 60 & $2,0 \%$ \\
Comunicação & 45 & $1,5 \%$ \\
Ciências sociais & 44 & $1,5 \%$ \\
Linguística & 41 & $1,4 \%$ \\
Outras áreas & 480 & $15,9 \%$ \\
Total & $\mathbf{3 0 2 0}$ & $\mathbf{1 0 0 \%}$ \\
\hline
\end{tabular}

Fonte: Elaborado pelos autores (2020).

Em uma análise evolutiva do período pesquisado, 1997 a 2016, observouse que a cada quinquênio analisado, a CI estrangeira passou a ter maior interesse por outras áreas do conhecimento, refletida nas citações concedidas à área por essas outras áreas. Essa constatação pode indicar que a CI internacional está num processo crescente de construção de um domínio teórico e metodológico disciplinar, caminhando para se tornar um campo maduro, com massa crítica evoluída e que o fato observado por Souza (2011) para quem o campo constrói seus laços interdisciplinares de forma unidimensional, a princípio, parece ter evoluído bastante. Entretanto, essa constatação ainda carece de estudos mais aprofundados para avaliar se esse aumento de citações da área pelas demais áreas é proveniente de um amadurecimento epistemológico do campo ou por outros motivos.

Esse "empréstimo" de conhecimento do campo a outras disciplinas, verificado via análise de citação, não permite identificar o nível de relação disciplinar (multi, inter ou transdisciplinar) estabelecida. Esta análise do nível de relação disciplinar será realizada na segunda etapa desta pesquisa. 


\subsection{Segunda etapa}

$\mathrm{Na}$ análise da primeira etapa foram levantadas ao todo 2.973 citações de documentos da área para o conhecimento produzido pela própria área na esfera internacional e 2.124 citações de documentos de áreas externas para artigos produzidos pela CI no cenário internacional.

Conforme pressuposto apresentado na seção 4, Metodologia, as 2.973 citações concedidas à área, provenientes de documentos da própria área, foram consideradas unidisciplinares e não foram objeto de estudo nessa pesquisa por não estarem contempladas nos seus objetivos.

As demais 2.124 citações de trabalhos de outras áreas para documentos produzidos pela CI no cenário internacional foram consideradas como construídas, a princípio, com base em alguma relação disciplinar (multi, inter ou transdisciplinar) com a CI internacional.

Para averiguar qual o tipo de relação disciplinar estabelecida foi necessária uma análise minuciosa nas citações aos artigos de CI dos periódicos internacionais investigados. Devido à quantidade de citações concedidas, optouse por fazer na segunda etapa uma análise em uma amostra não probabilística selecionada por conveniência de $15 \%$ das 2.124 citações, ou seja, uma amostra de 319 citações conforme explicado na metodologia.

$\mathrm{Na}$ análise referente ao número de autores (ver Gráfico 1), o resultado da análise da amostra revelou que dentre as 319 citações analisadas, 50 (15,7\%) eram de uma única autoria. O restante das 269 citações da amostra analisada foram trabalhos construídos por dois ou mais autores. Com dois autores obtiveram-se 85 (26,6\%) citações, com três autores obtiveram-se 79 (24,8\%) citações, com quatro autores obtiveram-se $49(15,4 \%)$ citações e com cinco ou mais autores foram 56 $(17,6 \%)$ citações. 
Gráfico 1 - Número de autores dos trabalhos das citações de outras áreas ao conhecimento de CI internacional verificado na amostra analisada

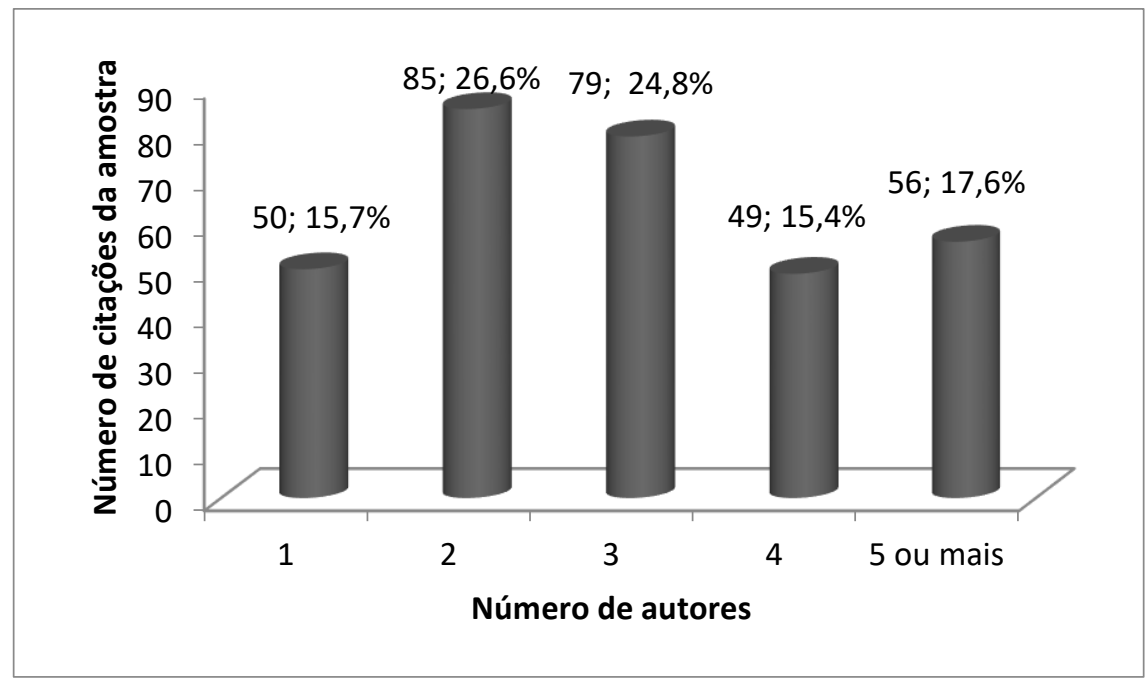

Fonte: Elaborado pelos autores (2020).

No que diz respeito à análise cruzada dos fatores área de atuação versus formação dos pesquisadores referentes às 50 citações da amostra provenientes de trabalhos que foram classificados como autoria única, o resultado da análise quantitativa, de acordo com os pressupostos adotados nessa pesquisa, revelou que trabalhos de cinco citações foram considerados unidisciplinares, trabalhos de 42 citações foram considerados multidisciplinares e trabalhos de três citações apresentaram propriedades indicativas de terem sido construídos a base de uma relação interdisciplinar. Por isso, esses trabalhos passaram por uma análise qualitativa, mediante leitura integral do texto e a utilização do guia adaptado de Bicalho (2009), com o objetivo de se determinar o real nível de relação/interação (multi, inter ou transdisciplinar) estabelecido nesses trabalhos.

O resultado dessa análise qualitativa revelou que, dentre as três citações representadas por trabalhos classificados como de autoria única avaliadas pela leitura integral do texto e da utilização do guia adaptado de Bicalho (2009), todas as três foram consideradas interdisciplinares.

A Tabela 6 sintetiza o resultado observado nas análises quali-quantitativas das 50 citações referentes aos trabalhos de autoria única que compuseram a amostra. 
Tabela 6 - Combinações utilizadas para determinação do tipo de relacionamento verificado nas citações da amostra provenientes de trabalhos com autoria única avaliadas para o cenário internacional

\begin{tabular}{|c|c|c|c|c|}
\hline $\begin{array}{l}\text { Número } \\
\text { de } \\
\text { autores }\end{array}$ & $\begin{array}{c}\text { Combinação de formação } x \\
\text { atuação }\end{array}$ & $\begin{array}{l}\text { Casos } \\
\text { obser- } \\
\text { vados }\end{array}$ & $\begin{array}{c}\text { Tipo de } \\
\text { relacionamento/ } \\
\text { interação } \\
\text { verificados } \\
\end{array}$ & $\begin{array}{c}\text { Modo de } \\
\text { determinação } \\
\text { do tipo de } \\
\text { relacionamento }\end{array}$ \\
\hline \multirow[t]{8}{*}{1 autor } & $\begin{array}{llr}\text { Formação } & \text { e } & \text { atuação } \\
\text { concomitante } & \text { somente } & \text { em } \\
\text { outra(s) área(s) } & & \end{array}$ & 42 & Multidisciplinar & $\begin{array}{l}\text { Pressupostos } \\
\text { (Quantitativo) }\end{array}$ \\
\hline & $\begin{array}{l}\text { Formação em outra(s) área(s) } \\
\text { mais atuação em outra(s) área(s) } \\
\text { mais CI }\end{array}$ & 2 & Interdisciplinar & $\begin{array}{l}\text { Leitura integral } \\
\text { do texto } \\
\text { (Qualitativo) }\end{array}$ \\
\hline & $\begin{array}{l}\text { Formação em outra(s) área(s) } \\
\text { mais atuação somente em CI }\end{array}$ & 0 & Não se aplica & $\begin{array}{l}\text { Pressupostos } \\
\text { (Quantitativo) }\end{array}$ \\
\hline & $\begin{array}{l}\text { Formação concomitante em } \\
\text { outra(s) área(s) mais CI mais } \\
\text { atuação em outra(s) área(s) mais } \\
\text { CI ou somente CI }\end{array}$ & 1 & Interdisciplinar & $\begin{array}{l}\text { Leitura integral } \\
\text { do texto } \\
\text { (Qualitativo) }\end{array}$ \\
\hline & $\begin{array}{l}\text { Formação concomitante em } \\
\text { outra(s) área(s) mais CI mais } \\
\text { atuação em outra(s) área(s) }\end{array}$ & 0 & Não se aplica & $\begin{array}{l}\text { Pressupostos } \\
\text { (Quantitativo) }\end{array}$ \\
\hline & $\begin{array}{l}\text { Formação e atuação } \\
\text { concomitante somente em CI }\end{array}$ & 5 & Unidisciplinar & $\begin{array}{l}\text { Pressupostos } \\
\text { (Quantitativo) }\end{array}$ \\
\hline & $\begin{array}{l}\text { Formação somente em CI mais } \\
\text { atuação em outra(s) área(s) }\end{array}$ & 0 & Não se aplica & $\begin{array}{l}\text { Pressupostos } \\
\text { (Quantitativo) }\end{array}$ \\
\hline & $\begin{array}{l}\text { Formação somente em CI mais } \\
\text { atuação em outra(s) área(s) mais } \\
\text { CI }\end{array}$ & 0 & Não se aplica & $\begin{array}{l}\text { Pressupostos } \\
\text { (Quantitativo) }\end{array}$ \\
\hline \multirow[t]{3}{*}{ Total } & & 42 & Multidisciplinar & Pressupostos e \\
\hline & & 3 & Interdisciplinar & leitura integral \\
\hline & & 5 & Unidisciplinar & $\begin{array}{l}\text { do texto } \\
\text { (Quanti/quali) }\end{array}$ \\
\hline
\end{tabular}

Fonte: Elaborado pelos autores (2020).

No que diz respeito à análise cruzada dos fatores área de atuação versus formação dos pesquisadores referentes as 269 citações da amostra provenientes de trabalhos que foram classificados como autoria múltipla, o resultado da análise quantitativa, de acordo com os pressupostos adotados nessa pesquisa, revelou que trabalhos de 15 citações foram considerados unidisciplinares, trabalhos de 227 citações foram considerados multidisciplinares e trabalhos 27 citações apresentaram propriedades indicativas de terem sido construídos a base de uma relação . Por isso, esses trabalhos passaram por uma análise qualitativa por meio da leitura integral do texto e a utilização do guia adaptado de Bicalho (2009) com o objetivo de se determinar o real nível de relação/interação (multi, inter ou transdisciplinar) estabelecido nos trabalhos dessas citações. 
O resultado dessa análise qualitativa revelou que dentre as 27 citações representadas por trabalhos classificados como de autoria múltipla avaliadas pela leitura integral do texto e da utilização do guia adaptado de Bicalho (2009), cinco foram consideradas unidisciplinares, quatro foram consideradas multidisciplinares e 18 interdisciplinares.

A Tabela 7 sintetiza o resultado observado nas análises quali-quantitativas das 269 citações referentes aos trabalhos de autoria múltipla que compuseram a amostra.

Tabela 7 - Combinações utilizadas para determinação do tipo de relacionamento verificado nas citações da amostra provenientes de pesquisas com autoria múltipla avaliadas para o cenário internacional

\begin{tabular}{|c|c|c|c|c|}
\hline $\begin{array}{l}\text { Número } \\
\text { de } \\
\text { autores }\end{array}$ & $\begin{array}{c}\text { Combinação de formação } x \\
\text { atuação }\end{array}$ & $\begin{array}{l}\text { Casos } \\
\text { obser- } \\
\text { vados }\end{array}$ & $\begin{array}{c}\text { Tipo de } \\
\text { relacionamento/ } \\
\text { interação } \\
\text { verificado } \\
\end{array}$ & $\begin{array}{c}\text { Modo de } \\
\text { determinação } \\
\text { do tipo de } \\
\text { relacionamento } \\
\end{array}$ \\
\hline \multirow[t]{8}{*}{$\begin{array}{c}2 \text { ou } \\
\text { mais } \\
\text { autores }\end{array}$} & $\begin{array}{llr}\text { Formação } & \text { e atuação } \\
\text { concomitante } & \text { somente } & \text { em } \\
\text { outra(s) área(s) } & & \end{array}$ & 227 & Multidisciplinar & $\begin{array}{l}\text { Pressupostos } \\
\text { (Quantitativo) }\end{array}$ \\
\hline & $\begin{array}{l}\text { Formação em outra(s) área(s) } \\
\text { mais atuação em outra(s) área(s) } \\
\text { mais CI }\end{array}$ & $\begin{array}{l}2 \\
2\end{array}$ & $\begin{array}{l}\text { Unidisciplinar } \\
\text { Interdisciplinar }\end{array}$ & $\begin{array}{l}\text { Leitura integral } \\
\text { do texto } \\
\text { (Qualitativo) }\end{array}$ \\
\hline & $\begin{array}{l}\text { Formação em outra(s) área(s), } \\
\text { mas atuação somente em CI }\end{array}$ & 0 & Não se aplica & $\begin{array}{l}\text { Pressupostos } \\
\text { (Quantitativo) }\end{array}$ \\
\hline & $\begin{array}{l}\text { Formação concomitante em } \\
\text { outras áreas mais CI mais } \\
\text { atuação em outra(s) área(s) mais } \\
\text { CI ou somente CI }\end{array}$ & $\begin{array}{r}16 \\
4 \\
3\end{array}$ & $\begin{array}{l}\text { Interdisciplinar } \\
\text { Multidisciplinar } \\
\text { Unidisciplinar }\end{array}$ & $\begin{array}{l}\text { Leitura integral } \\
\text { do texto } \\
\text { (Qualitativo) }\end{array}$ \\
\hline & $\begin{array}{l}\text { Formação concomitante em } \\
\text { outras áreas mais CI mais } \\
\text { atuação em outra(s) área(s) }\end{array}$ & 0 & Não se aplica & $\begin{array}{l}\text { Pressupostos } \\
\text { (Quantitativo) }\end{array}$ \\
\hline & $\begin{array}{l}\text { Formação e atuação } \\
\text { concomitante somente em CI }\end{array}$ & 15 & Unidisciplinar & $\begin{array}{l}\text { Pressupostos } \\
\text { (Quantitativo) }\end{array}$ \\
\hline & $\begin{array}{l}\text { Formação somente em CI mais } \\
\text { atuação em outra(s) área(s) }\end{array}$ & 0 & Não se aplica & $\begin{array}{l}\text { Pressupostos } \\
\text { (Quantitativo) }\end{array}$ \\
\hline & $\begin{array}{l}\text { Formação somente em CI mais } \\
\text { atuação em outra(s) área(s) mais } \\
\text { CI }\end{array}$ & 0 & Não se aplica & $\begin{array}{l}\text { Pressupostos } \\
\text { (Quantitativo) }\end{array}$ \\
\hline Total & & $\begin{array}{r}231 \\
18 \\
20\end{array}$ & $\begin{array}{l}\text { Multidisciplinar } \\
\text { Interdisciplinar } \\
\text { Unidisciplinar }\end{array}$ & $\begin{array}{l}\text { Pressupostos e } \\
\text { leitura integral } \\
\text { do texto } \\
\text { (Quanti/quali) }\end{array}$ \\
\hline
\end{tabular}

Fonte: Elaborado pelos autores (2020).

Ao final, o resultado da análise quantitativa, realizada nas citações referentes aos 319 trabalhos da amostra classificados como autoria única e 
múltipla revelou que trabalhos de 20 citações foram considerados unidisciplinares, trabalhos de 269 citações foram considerados multidisciplinares e trabalhos de 30 citações apresentaram propriedades indicativas de terem sido construídos a base de uma relação interdisciplinar e, por isso, passaram por uma análise mais aprofundada por meio da leitura integral do texto e da utilização do guia adaptado de Bicalho (2009) com o objetivo de se determinar o real nível de relação/interação (multi, inter ou transdisciplinar) estabelecido nos trabalhos dessas citações.

O resultado total da análise qualitativa revelou que dentre as 30 citações representadas por trabalhos classificados com autoria única e múltipla avaliadas pela leitura integral do texto e da utilização do guia adaptado de Bicalho (2009), cinco foram consideradas unidisciplinares, quatro foram consideradas multidisciplinares e 21 interdisciplinares.

Com a finalidade de facilitar a visualização, a Tabela 8 sintetiza o resultado observado nas análises quali-quantitativas de todas as 319 citações referentes aos trabalhos de autoria única e múltipla que compuseram a amostra em âmbito internacional.

Tabela 8 - Tipo de relacionamento verificado a partir das análises quali-quantitativas realizadas nas 319 citações referentes a trabalhos de autoria única e múltipla que compuseram a amostra

\begin{tabular}{crll}
\hline Número de autores & $\begin{array}{c}\text { Casos } \\
\text { observados }\end{array}$ & $\begin{array}{c}\text { Tipo de } \\
\text { relacionamento/ } \\
\text { interação verificado }\end{array}$ & $\begin{array}{l}\text { Modo de } \\
\text { determinação } \\
\text { do tipo de } \\
\text { relacionamento }\end{array}$ \\
\hline $\begin{array}{c}\text { Subtotal referente às 50 } \\
\text { pesquisas da amostra de }\end{array}$ & 42 & Multidisciplinar & $\begin{array}{l}\text { Pressupostos e } \\
\text { autoria única }\end{array}$ \\
$\begin{array}{c}\text { leitura integral } \\
\text { do texto } \\
\text { (Quanti/quali) }\end{array}$ \\
$\begin{array}{c}\text { Subtotal referente às 269 } \\
\text { pesquisas da amostra de }\end{array}$ & 5 & Unidisciplinar & $\begin{array}{l}\text { Pressupostos e } \\
\text { autoria múltipla }\end{array}$ \\
$\begin{array}{c}\text { leitura integral } \\
\text { do texto } \\
\text { Total geral dos resultados } \\
\text { das análises quali- }\end{array}$ & 231 & Multidisciplinar & Interdisciplinar \\
$\begin{array}{c}\text { quantitativas das 319 } \\
\text { pesquisas da amostra }\end{array}$ & $\mathbf{2 7 3}$ & Multidisciplinar & $\begin{array}{l}\text { Pressupostos e } \\
\text { leitura integral } \\
\text { do texto } \\
\text { (Quanti/quali) }\end{array}$ \\
\hline
\end{tabular}

Fonte: Elaborado pelos autores (2020). 
Ainda que os dados da amostra não possam ser generalizados para a população, uma vez que utilizou-se o método de amostragem não-probabilística, seus resultados parecem indicar que um percentual razoável das citações referentes aos trabalhos de outras áreas à literatura de CI produzida nos periódicos internacionais de CI analisados foram desenvolvidas a base de alguma interação com a área, uma vez que 294 citações, o que equivale a 92,16\% dos trabalhos das 319 citações da amostra, apresentaram essa característica. Porém, na avaliação do tipo de relacionamento efetuado verificou-se que a porcentagem dos trabalhos das citações que efetivamente podem ser considerados interdisciplinares com a CI foi pequena - 21 trabalhos-, ou seja, 6,58\% dos trabalhos das 319 citações da amostra analisada, fato que não sustenta a característica interdisciplinar da CI a partir dos trabalhos das citações de outras áreas que estabeleceram alguma relação com o campo em âmbito internacional.

Mesmo que a pesquisa tenha adotado o pressuposto de que seria praticamente impossível de ser efetivado algum tipo de relação transdisciplinar, esse tipo de relação foi avaliada nos trabalhos das 30 citações que passaram pela análise qualitativa, os quais, devido às suas características, seriam os mais propensos a apresentarem, além de uma relação interdisciplinar, também uma relação transdisciplinar. Ao final da análise não foi encontrada uma relação transdisciplinar nos trabalhos das citações avaliadas.

\section{Conclusões}

Verificou-se uma relação disciplinar distinta a cada quinquênio, medida a partir das citações concedidas por trabalhos das demais áreas do conhecimento à área de CI.

Em todo o período avaliado, 1997 a 2016, verificou-se que as disciplinas externas que mais se relacionaram com a CI foram, respectivamente, educação, ciência da computação, psicologia, administração e medicina.

As citações ao conhecimento de CI na literatura internacional refletiram justamente a relevância atingida pelas diferentes temáticas trabalhadas pela área, tanto quinquênio a quinquênio quanto nesses últimos 20 anos somados, 
destacando-se as temáticas de cunho tecnológico como a questão da tecnologia da informação, os sistemas de recuperação da informação, as bases de dados e bibliotecas digitais/virtuais. $\mathrm{E}$ as de cunho humanistas como a comunicação científica, o letramento informacional e a biblioteca escolar.

A pesquisa verificou a existência de uma justificativa/característica potencializadora de realização de pesquisas interdisciplinares com a área, a saber: a questão de seu conhecimento também ser amplamente utilizado pelas demais áreas científicas.

Na etapa desta pesquisa, que visou identificar o tipo de interação (multi, inter ou transdisciplinar) estabelecida entre as demais áreas e a CI internacional, verificou-se que o percentual dos trabalhos das citações da amostra avaliados com base em uma relação interdisciplinar com a CI foi de 6,58\%. Considera-se que este percentual de trabalhos das citações de outras áreas que estabeleceram alguma relação com a CI não é suficiente para caracterizar a área como interdisciplinar. Estudos mais aprofundados se fazem necessários, uma vez que, devido à metodologia utilizada, amostragem não-probabilística, essa constatação não pode ser conclusiva e apenas permite a geração de hipóteses.

Assim como verificado por Bicalho (2009), ao analisar as relações estabelecidas na práxis científica da CI no cenário nacional, esta pesquisa também constatou, a partir da amostra analisada, que o nível de interação disciplinar estabelecido entre os trabalhos de outras áreas que citaram o conhecimento da CI internacional foi majoritariamente multidisciplinar, uma vez que em 85,58\% dos trabalhos da amostra analisada foram identificados esse tipo de relação.

É possível afirmar, a partir dos dados da amostra analisada, que a maioria dos trabalhos de áreas externas à CI que usaram o conhecimento da área no cenário internacional, o fizeram apenas para dar sustentação a sua disciplinaridade, ou seja, os trabalhos das disciplinas citantes apenas buscaram fundamentação epistemológica e metodológica na CI internacional para completar alguma lacuna epistemológica/metodológica existente nessas áreas externas. No entanto, não ocorreu uma integração de teorias e metodologias, nem a interlocução entre pesquisadores que propiciassem um enriquecimento mútuo 
entre as disciplinas e pessoas envolvidas, condição necessária para a efetivação de um trabalho interdisciplinar.

A literatura científica sobre a temática interdisciplinaridade apresenta uma série de resistências/obstáculos ao empreendimento de uma pesquisa interdisciplinar, a saber: o institucional, o epistemológico, o psicossociológico, o cultural, o metodológico, o de formação profissional e o material (BRIGGS; MICHAUD, 1972; FAZENDA, 2011; GUSDORF ${ }^{2}$ (1968 apud JAPIASSU, 1976); GUSDORF, 2006).

Foi possível constatar ainda, no período investigado, um suposto avanço epistemológico atingido pela área de CI no cenário internacional que já mantém um nível de relação disciplinar no qual a área assumiu também o papel de fornecedora de conhecimentos para as demais áreas, não sendo apenas a receptora como indicado por trabalhos passados (BICALHO, 2009; PAIM et al., 2001; SANTANA, 2012; SOUZA, 2011). Esse possível avanço epistemológico mapeado nessa pesquisa já havia sido observado também por outros trabalhos como o de Tang (2004) e permitiria a área de CI efetivar também pesquisas interdisciplinares com essas demais áreas.

Então, infere-se que, ou essa provável evolução epistemológica do campo disciplinar da CI, alcançada nesses últimos anos, não tenha ocorrido e o campo ainda possua uma tímida disciplinaridade, como apontou, por exemplo, Bicalho (2009) e Souza (2011), ou realmente tenha ocorrido a provável evolução epistemológica, mas ela ainda não seja capaz de promover uma pesquisa interdisciplinar entre as demais áreas do conhecimento e a CI, ou que a evolução realmente tenha ocorrido ao ponto de propiciar à área a efetuar pesquisas interdisciplinares. Neste caso, então a questão para a não efetivação de pesquisas interdisciplinares entre as outras áreas e a CI, como verificado na amostra analisada, seja outra, como a superação das barreiras registradas na literatura, que dificultam a realização de pesquisas interdisciplinares.

Os resultados também demonstraram que o simples levantamento de disciplinas, que utilizam o conhecimento da CI como metodologia para avaliar o nível de relação disciplinar, seria uma metodologia frágil e bem semelhante à metodologia utilizada por vários pesquisadores que avaliam a 
interdisciplinaridade da área a partir somente do levantamento de outras áreas utilizadas pela CI. Uma vez que esse método consegue, no máximo, apontar que houve uma correlação entre as áreas, mas não permite determinar o alcance da correlação. Se esse método tivesse sido utilizado para avaliar o tipo de interação estabelecida entre as demais áreas e a CI internacional, teria levado os resultados dessa pesquisa a um falso positivo, uma vez que consideraria todas as citações de outras disciplinas à CI (48,7\% das citações avaliadas) como interdisciplinares.

Nessas perspectivas, o resultado da pesquisa trouxe insumos concretos que validam as reflexões daquela corrente de pesquisadores que contestam as metodologias utilizadas nos estudos sobre interdisciplinaridade na área (GOMES, 2001; SANTOS NETO et al., 2017) e também para a corrente que defende que o campo não seja interdisciplinar (BICALHO, 2009; HIGINO; DUMONT, 2012; PAIM, et al., 2001; SANTANA, 2012).

\section{Referências}

BERTI, Valdir Pedro. Interdisciplinaridade: um conceito polissêmico. 2007. Dissertação (Mestrado em Ensino de Ciências) - Universidade de São Paulo, São Paulo, 2007.

BICALHO, Lucinéia Maria. As relações interdisciplinares refletidas na literatura brasileira da Ciência da Informação. 2009. Tese (Doutorado em Ciência da Informação) - Escola de Ciência da Informação, Universidade Federal de Minas Gerais, Belo Horizonte, 2009.

BORKO, Harold. Information science: what is it? American Documentation, [s.l.], v. 19, n. 1, p. 3-5, 1968.

BRIGGS, Asa; MICHAUD, Guy. Problèmes et solutions. In: OCDE. Problemes d'enseignement et de recherche dans les universités. Paris: OCDE, 1972. p. 191-265.

CHANG, Yu-Wei; HUANG, Mu-Hsuan. A study of the evolution of interdisciplinarity in library and information science: using three bibliometric methods. Journal of the American Society for Information Science and Technology, [s. l.], v. 63, n. 1, p. 22-33, 2012.

CROSLAND, Dorothy Murray. Georgia Tech and the NSF study grant for training personnel for scientific and technical libraries. Special Library, [s. l.], n. 53, p. 590-594, 1962. 
DING, Nan; PAN, Youneng; YANG, Chunyan. The interdisciplinarity of iSchools: an analysis and visualization of research publications. Malaysian Journal of Library \& Information Science, Kuala Lumpur, v. 21, n. 2, p. 21$39,2016$.

DOMINGUES, Ivan. Em busca do método. In: DOMINGUES, Ivan (org.) Conhecimento e transdisciplinaridade II: aspectos metodológicos. Belo Horizonte: Editora UFMG, 2005. p. 17-40.

FAZENDA, Ivani Catarina Arantes. Integração e interdisciplinaridade no ensino brasileiro: efetividade ou ideologia. 6. ed. São Paulo: Edições Loyola, 2011.

FERNANDES, Wesley Rodrigo. Desvendando as relações de outras disciplinas com a ciência da informação: um estudo comparativo entre a pesquisa nacional e internacional. 2019. Tese (Doutorado em Gestão e Organização do Conhecimento) - Escola de Ciência da Informação, Universidade Federal de Minas Gerais, Belo Horizonte, 2019.

GOMES, Henriette Ferreira. Interdisciplinaridade e Ciência da Informação: de característica a critério delineador de seu núcleo principal. DataGramaZero, Rio de Janeiro, v. 2, n. 4, p. 1-7, 2001.

GUSDORF, Georges. Conhecimento interdisciplinar. In: POMBO, Olga; GUIMARAES, Henrique Manuel; LEVY, Teresa (org.). Interdisciplinaridade: antologia. Porto: Campo das Letras, 2006. p. 37-58.

HIGINO, Anderson Fabian Ferreira; DUMONT, Lígia Maria Moreira. Ciência da Informação e interdisciplinaridade no contexto brasileiro: um estudo qualiquantitativo com foco no ENANCIB. In: ENCONTRO NACIONAL DE PESQUISA EM CIÊNCIA DA INFORMAÇÃO, 13., 2012, Rio de Janeiro. Anais [...]. Rio de Janeiro: Fiocruz, 2012. 1 CD-ROM.

HUANG, Mu-Hsuan; CHANG, Yu-Wei. A study of interdisciplinarity in information science: using direct citation and co-authorship analysis. Journal of Information Science, [s. l.], v. 37, n. 4, p. 369-378, 2011.

HUANG, Mu-Hsuan; CHANG, Yu-Wei. A comparative study of interdisciplinary changes between information science and library science. Scientometrics, [s.l.], v. 91, p. 789-803, 2012.

JANTSCH, Erich. Vers línterdisciplinarité et la transdiciplinarité das dans l'enseignement et l'innovation. In: OCDE. Problemes d'enseignement et de recherche dans les universités. Paris: OCDE, 1972. p. 98-124.

JAPIASSU, Hilton. Interdisciplinaridade e patologia do saber. Rio de Janeiro: Imago, 1976. 
MORAES, Marcos; CARELLI, Ana Esmeralda. A interdisciplinaridade na ciência da informação pela perspectiva da análise de citações. Em Questão, Porto Alegre, v. 22, n. 1, p. 137-160, 2016.

NICOLESCU, Basarab. O manifesto da transdisciplinaridade. 2. ed. São Paulo: Triom, 2001.

PAIM, Isis et al. Interdisciplinaridade na ciência da informação: início de um diálogo. Perspectivas em Ciência da Informação, Belo Horizonte, v. 6, n. 1, p. 19-26, 2001.

PIAGET, Jean. L'epistemologie dês relations interdisciplinaires. In: OCDE. Problemes d'enseignement et de recherche dans les universités. Paris: OCDE, 1972. p. 131-144.

PINHEIRO, Lena Vânia Ribeiro. Mutações na Ciência da Informação e reflexos nas mandalas interdisciplinares. Informação e Sociedade: estudos, João Pessoa, v. 28, n. 3, p. 115-134, 2018.

PINHEIRO, Lena Vânia Ribeiro. Pilares conceituais para mapeamento do território epistemológico da Ciência da Informação: disciplinaridade, interdisciplinaridade, transdisciplinaridade e aplicações. In: BENTES PINTO, Virgínia; CAVALCANTE, Lídia Eugênia; SILVA NETO, Casemiro (org.). Ciência da Informação: abordagem transdisciplinares: gênese e aplicações. Fortaleza: Edições UFC, 2007. p. 71-104.

PINHEIRO, Lena Vania Ribeiro; LOUREIRO, José Mauro Mattheus. Traçados e limites da Ciência da Informação. Ciência da Informação, Brasília, v. 24, n. 1, p. 42-53, 1995.

POMBO, Olga. Epistemologia da interdisciplinaridade. Ideação: Revista do Centro de Educação e Letras da UNIOLESTE, Foz do Iguaçu, v. 10, n.1, p. 940, 2008.

POMBO, Olga. Interdisciplinaridade: ambições e limites. Lisboa: Antropos, 2004.

REPKO, Allen F. Defining Interdisciplinary Studies. In: REPKO, Allen F. Interdisciplinary Research: process and theory. Los Angeles: Sage, 2008. p. 326.

REPKO, Allen F. Defining Interdisciplinary Studies. In: REPKO, Allen F. Interdisciplinary Research: process and theory. 2. ed. Los Angeles: Sage, 2012. p. 3-26.

SANTANA, Glessa Heryka Celestino de. A Ciência da Informação e sua consolidação em face da interdisciplinaridade. Encontros Bibli: revista 
eletrônica de biblioteconomia e ciência da informação, Florianópolis, v. 17, n. 35 , p. 1-26, 2012.

SANTOS NETO, João Arlindo dos et al. Interdisciplinaridade no contexto da Ciência da Informação: correntes e questionamentos. Em Questão, Porto Alegre, v. 23, n. 1, p. 9-35, 2017.

SARACEVIC, Tefko. Ciência da informação: origem, evolução e relações. Perspectivas em Ciência da Informação, Belo Horizonte, v. 1, n. 1, p. 41-62, 1996.

SHERA, Jesse Hauk; CLEVELAND, Donald B. History and foundations of Information Science. Annual Review of Information Science and Technology, [s. l.], v. 12, p. 249-275, 1977.

SILVA, Jonathas Luiz Carvalho. Das concepções disciplinares na Ciência da Informação e/ou de suas configurações epistemológicas: o desiderato percepcionado da interdisciplinaridade. Investigación Bibliotecológica, Ciudad de México, v. 27, n. 59, p. 67-92, 2013.

SOUZA, Edivanio Duarte de. A epistemologia interdisciplinar na ciência da informação: dos indícios aos efeitos de sentido na consolidação do campo disciplinar. 2011. Tese (Doutorado em Ciência da Informação) - Escola de Ciência da Informação, Universidade Federal de Minas Gerais, Belo Horizonte, 2011.

TANG, Rong. Evolution of the interdisciplinary characteristics of information and library science. Proceedings of the American Society for Information Science and Technology, [s. l.], v. 41, n. 1, p. 54-63, 2004.

TAYLOR, Robert Saxton. Professional aspects of information science and technology. Annual Review of Information Science and Technology, [s. l.], v. 1, p. 15-40, 1966.

ZIMMERMANN, Érika; CARLOS, Jairo Gonçalves. Interdisciplinaridade e ensino de física: quais as possibilidades? In: SIMPÓSIO NACIONAL DE ENSINO DE FÍSICA, 16., 2005, Rio de Janeiro. Anais [...]. Rio de Janeiro: SNEF, 2005. p. 1-5. 


\title{
Unraveling the relations of other disciplines with information science: evaluation from an international perspective
}

\begin{abstract}
This article aimed to investigate in the scientific literature the use of knowledge produced by international information science by researchers from other scientific areas. The research was conducted in two stages. The data analyzed in the first stage came from a study of citations to articles in the area of information science from the international sphere published between 1997 and 2016. Web of Science was used to gather this data. In the second stage, aiming to determine the type of relationship (multi, inter or transdisciplinary) established between citations from other disciplines and information science, a quantitative analysis was performed in a convenience non-probabilistic sample of $15 \%$ of the citations of other disciplines to works from international information science identified in the first stage. Furthermore, in the sample used in the second stage, for works of citations that showed properties indicating that research was built on the basis of an interdisciplinary relationship, a qualitative analysis was performed to determine if they were uni, inter, multi or transdisciplinary in nature. As a main result it should be highlighted that there was a growing trend of citations of international information science papers by other scientific areas. This fact may demonstrate that mondial information science has advanced theoretically and methodologically in the last 20 years. Additionally, results show an expressive use of mondial information science knowledge by the other areas of knowledge which could indicate a potential interdisciplinary relationship of other disciplines with international information science. However, this potential interdisciplinary relationship was not confirmed by the quantitative and qualitative analysis performed in the second stage of the research.
\end{abstract}

Keywords: Information Science. Interdisciplinarity. Transdisciplinarity. Pluridisciplinarity. Epistemology of Information Science.

Recebido: 07/05/2020

Aceito: 21/09/2020

\section{Declaração de autoria}

Concepção e elaboração do estudo: Wesley Rodrigo Fernandes, Beatriz Valadares Cendón

Coleta de dados: Wesley Rodrigo Fernandes

Análise e discussão de dados: Wesley Rodrigo Fernandes, Beatriz Valadares Cendón

Redação e revisão do manuscrito: Wesley Rodrigo Fernandes, Beatriz Valadares Cendón 


\section{Como citar}

FERNANDES, Wesley Rodrigo; CENDÓN, Beatriz Valadares. Desvendando as relações de outras disciplinas com ciência da informação: avaliação a partir da perspectiva internacional. Em Questão, Porto Alegre, v. 27, n. 2, p. 76-116, abr./jun. 2021.

Doi: http://dx.doi.org/10.19132/1808-5245272.76-116

1 De acordo com o nível da tabela de área do conhecimento adotado nessa pesquisa para classificação das áreas de conhecimento, todos os autores formados ou atuantes em alguma das subáreas da ciência da informação a saber: teoria da informação, biblioteconomia e arquivologia, foram classificados como formados ou atuantes em ciência da informação.

${ }^{2}$ GUSDORF, Georges. Interdisciplinaire (connaissance). Enciclopaedia Universalis, Paris, v. 8, p. 1086-1090, 1968. Apud Japiassu (1976). 